basis for a great story. But The Jasons rings few dramatic bells. And the author observes: "Jasons think they've done the country good, but they haven't got much clear evidence."

Perhaps a more sceptical attitude towards the Jasons in particular and the advisory process in general would have paid off. My own observation is that politicians seek scientific advice to support their preconceptions, not to steer them to wisdom. But where secrecy previously obscured public view of the Jasons, reverence is the problem here. Stockholm

\title{
A journey to remember
}

\section{In Search of Memory: The Emergence of a New Science of Mind \\ by Eric R. Kandel \\ W. W. Norton: 2006.510 pp. \$29.95}

\section{Yadin Dudai}

Few can interlace their autobiography with the evolution of a scientific paradigm. Even fewer can weave such a story seamlessly. Eric Kandel is one of these. His career, from his training in Harry Grundfest's laboratory at Columbia University in New York more than fifty years ago to a remarkably productive present, also at Columbia, epitomizes his ardent reductionist approach to the neural sciences. Its formal pinnacle was the Nobel Prize in Physiology or Medicine, which Kandel shared in 2000 with Arvid Carlsson and Paul Greengard for their discoveries concerning signal transduction in the nervous system.

Kandel's intellectual journey in neuroscience can be traced back to his first encounter with Grundfest. The enthusiastic medical student, with a strong background in history and literature, proposes unveiling the brain substrates of Freud's three psychic structures, the ego, superego and id, in six months. Grundfest, the seasoned professor of neurology, suggests a different agenda, no less grandiose: to understand the mind, he replies, we need to look at the brain one cell at a time. The narrative of the brain sciences in the past century is made up of attempts to negotiate between these two extremes. In his admirable personal version of this narrative, Kandel is still a grundfestian, but appreciates that the bottom-up approach still has a long way to go.

Nowhere, perhaps, is this conflict between reductionism and global approaches to the brain more evident than in memory research. Memory is a term applied nowadays to a wide gamut of functions, ranging from experiencedependent modification of reflexes in brainless organisms to the recollection of personal syndrome is not confined to hostages who become enamoured of their captors: it can also afflict observers who fall for their subjects. As Finkbeiner wrote of an anonymous Jason identified only as "Dr. Y": "She might look plain if she didn't move so gracefully, and intense and honest to the bone."

Daniel S. Greenberg is a journalist in

Washington. His new book, Science for Sale, will be published next year by the University of Chicago Press. and if she didn't sit so quietly, self-possessed

events in their investigators. Even if such an inclusive definition is accepted, the distinction should still be made between memory as a process and as an item with mental content.

The process is assumed to be subserved by the plasticity of synapses, the functional contacts between nerve cells. One could further assume that the basic building blocks of the plasticity machinery were conserved in evolution. If this is the case, why not approach memory by studying its simplest forms in the simplest of organisms? This philosophy has guided Kandel and given the timid sea-slug Aplysia a prominent position in textbooks of neuroscience. The approach, anchored in the achievements of molecular biology, has proved highly productive in identifying plasticity mechanisms that subserve memory. What it doesn't address satisfactorily is the content and meaning of memory items. This requires an understanding of how brains encode specific pieces of mental information. Many would argue that this calls for the spatiotemporal codes of neuronal populations to be deciphered. Further- more, given the immense difference in complexity and the likelihood of emergent properties, it is unlikely that probing the ganglia of Aplysia can tell us how our brain recalls our first love or our father's face.

Nevertheless, the reductionist approach to behavioural plasticity, of which Kandel's work is the prime example, is a success story that has given us models of molecular and cellular plasticity that propose how experience affects nerve cells. It is now for those who follow Kandel to link the molecular and cellular level with the systems level of analysis. This integration is the major challenge facing the science of memory, and might require, in addition to new methodologies, a change of zeitgeist or an amalgamation of approaches.

Kandel's book is enthusiastically recommended as a captivating account of the career of a prominent leader in contemporary neuroscience. The author is not only an authoritative scholar but also a marvellous popularizer and narrator, who brings to the story an attractive mix of facts, personal touches and wisdom, seasoned with reflective humour. But In Search of Memory is not just about science: it is also about history and identity. Kandel is a devoted scientist, humanist, family man and proud Jew. He follows, by his own definition, the "Talmudic tradition writ large. But rather than annotate a religious text, we annotate texts written by evolutionary processes working over hundreds of millions of years."

Kandel was just a child when he emigrated from Austria to the United States, but the Holocaust and the trauma of European Jewry are deeply embedded in his memory. His contempt for racism is clear. In the background hovers the terrible awareness that many of his generation perished, unknown, in concentration camps before they had a chance to explore and contribute to the world. When the Austrian president contacts Kandel and expresses his desire to honour the new Nobel laureate of Viennese origin, Kandel's reaction is to organize a symposium in

Vienna to acknowledge Austria's central role in the Nazi atrocities and evaluate the significance for scholarship of the disappearance of the Jewish community in Vienna. Kandel's accounts of incidents during this visit to Vienna should be read carefully by those who ignore lingering undercurrents of anti-Semitism.

The Greek poet Constantine Cavafy, in his poem Ithaka, which recounts the return of Odysseus to his homeland, advises his hero not to hasten:

As you set out for Ithaka,

Hope the voyage is long,

Full of adventure, full of discovery...

Better if it lasts for years...

Ithaka gave you the marvellous

Without her you would not have journey sailed away. 
The reward, according to Cavafy, is the journey, rather than the goal. Both the young Kandel who met Grundfest and the mature, imaginative investigator of the Aplysia epoch seem to have valued the goal at least as much as the journey. But reading these memoirs, one senses that, over the years, Kandel's appreciation of the journey itself has increased. Is Ithaka attainable for those who study memory?
If the goal is to chart and analyse plasticity in neuronal terrain in fine detail, then the kandelian Aplysia paradigm is a tremendous leap forwards. If it is to understand how recollecting humans think, feel and plan, we might need more Kandels.

Yadin Dudai is in the Department of

Neurobiology, Weizmann Institute of Science,

Rehovot 76100, Israel.

\section{The ant trail}

\author{
Nature Revealed: Selected Writings, \\ 1949-2006 \\ by Edward O. Wilson \\ Johns Hopkins University Press: 2006. \\ 736 pp. $\$ 35$
}

\section{Laurent Keller}

Edward O. Wilson is one of the most distinguished scientists and thinkers of our time. He is best known for his twenty or so books, exploring topics as diverse as sociobiology, human nature, ant taxonomy, biodiversity and the philosophy of knowledge, but he has also published a large number of scientific articles and other works. Nature Revealed, a compilation of 60 of these articles, illustrates how his interest has ranged between fields as diverse as entomology, ethology and philosophy.

Wilson's first publication was in 1949 in a local journal called Alabama Conservation. In this paper, Wilson, then a 19-year-old senior at the University of Alabama, reports the distribution of what was then called the imported fire ant. His second article was published in Evolution, an influential scientific journal. In this article Wilson reports that there are two phenotypic variants of the imported fire ant. By switching queens from one colour-type colony to the other, he proved a hereditary basis for the phenotypic differences observed and proposed several explanations for how one morph replaced the other. Incidentally, later studies revealed that the two colour morphs are actually two distinct species, now called the black imported fire ant (Solenopsis richteri) and the red imported fire ant (Solenopsis invicta), the latter of which has become one of the worst invasive pest species in the world.

The difference in the content of these two articles foreshadows Wilson's main gift: his ability to be hugely integrative and make bold syntheses. In the scant two years that separated the publication of these two reports, Wilson had vastly broadened his interests, allowing him to interpret his field observations within a solid framework of evolutionary biology and population genetics.

The progression of articles in Nature Revealed demonstrates, again and again, Wilson's endless capacity to put scientific findings into a broader context and to bridge gaps between disciplines. For example, between
1959 and 1962 he published a few specialized papers detailing the nature of communication within ant societies. By 1963 he had realized that pheromones were important, and had ventured to propose general principles in a Scientific American article entitled simply "Pheromones". In this piece, Wilson also speculated for the first time on the existence of human pheromones. On the basis of data by French biologist J. LeMagnen, who showed that the odour of exaltolide can only be perceived clearly by sexually mature women at the time of ovulation, Wilson stated that although these observations "hardly represent a case for the existence of human pheromones...they do suggest that the relation of odours to human physiology can bear further examinations". Such examinations did indeed reveal that pheromones are implicated in some human behaviours.

In the same vein, the sequence of publications reveals the steps that led Wilson from reports of patchy ant distributions in the rainforests of New Guinea to the synthesis with Robert MacArthur of the influential theory of island biogeography. Similarly, the content of several articles demonstrates Wilson's growing concerns with biodiversity loss and his contributions to the development of the fledgling field of environmental ethics.

Each article is preceded by a brief essay in which Wilson explains its context and outlines more recent developments in the field. Although not as thorough and telling as those by W. D. Hamilton in Narrow Roads of Gene Land, vols 1-3 (Oxford University Press, 1997-2005), these brief essays are interesting and informative about some essentials of Wilson's personality. For example, Wilson explains that he revised the ant genus Pheidole as "a hobby, a form of relaxation" during which he "listened to classical and soft rock music... at odd hours" in his home laboratory. The outcome was Pheidole in the New World (Harvard University Press, 2003), an 800-page monograph with more than 5,000 drawings and a list of 624 species, of which 337 are new to science (see Nature 424, 727; 2003) — an achievement beyond what most scientists would ever dream of accomplishing in a lifetime.

Nature Revealed contains all 60 articles in their original form. Unfortunately, the size reduction of several articles resulted in print so small as to be reminiscent of the labels on insect museum specimens. The diversity and technical nature of some of the articles might make this book difficult to read from cover to cover, but it remains a treasure for those interested in science and history. The progression of articles highlights the path of Wilson's journey across different disciplines in an attempt to bridge gaps between them, including the gulf between the humanities and the sciences. These are important messages in this age of ultraspecialization and disciplinary compartmentalization.

Laurent Keller is in the Department of Ecology and Evolution, Biophore, University of Lausanne, Lausanne 1015, Switzerland.

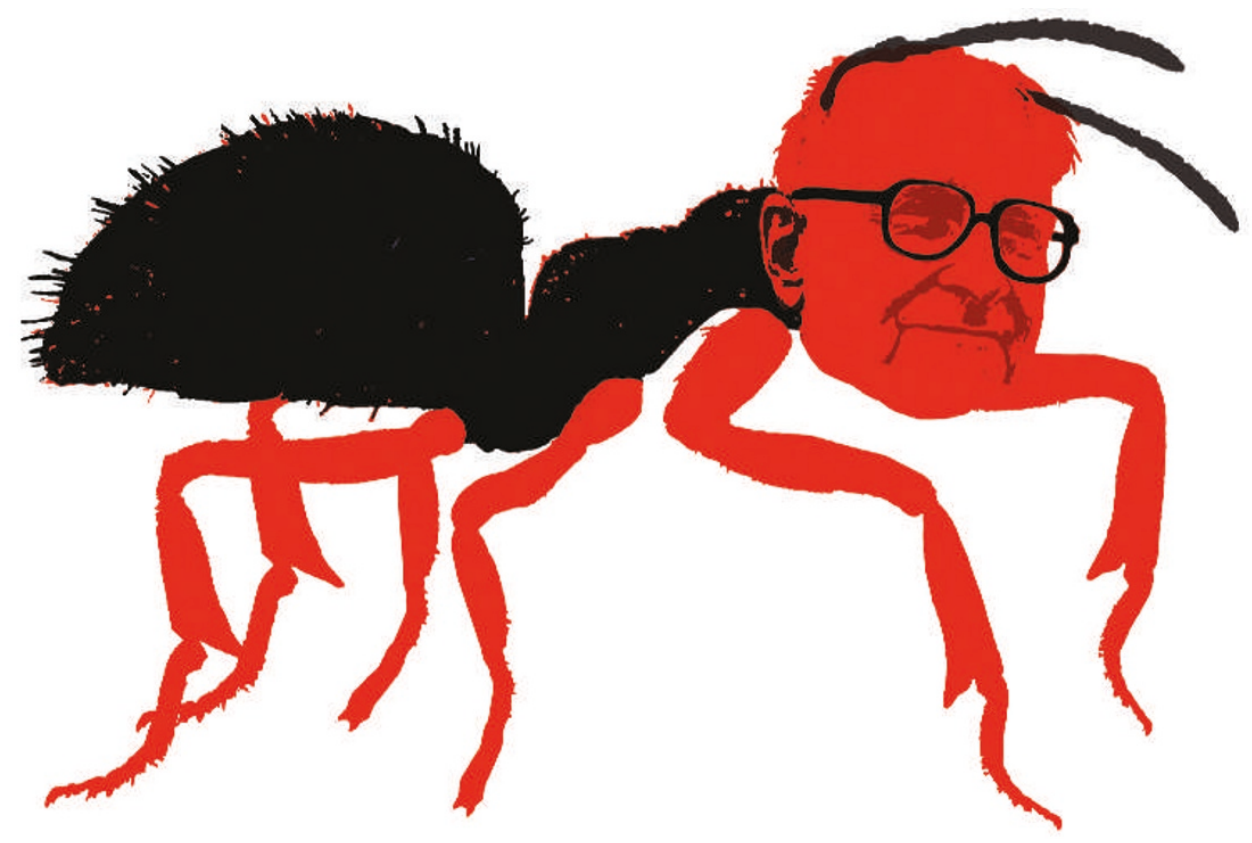

